\title{
Inflammatory Fibroid Polyp of the Small Intestine: a Case Report and Systematic Literature Review
}

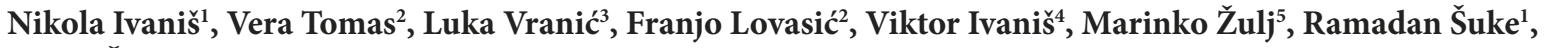 \\ Davor Štimac ${ }^{3}$
}

\author{
1) Private Medical Centre \\ Rijeka, Polyclinic Ivaniš, \\ Rijeka; \\ 2) Department of \\ Anesthesiology and Intensive \\ Care Unit, Clinical Hospital \\ Centre Rijeka, Rijeka; \\ 3) Department of \\ Gastroenterology, Clinical \\ Hospital Centre Rijeka, Faculty \\ of Medicine, University of \\ Rijeka, Rijeka; \\ 4) Thalassotherapia Opatija, \\ Opatija; \\ 5) Faculty of Dental Medicine \\ and Health Osijek, University \\ of Osijek, Croatia
}

\begin{abstract}
Aim: Starting from a case presentation, this review aims to present literature data on inflammatory fibroid polyps (IFPs) of the small intestine.

Methods: Case report and systematic review. A comprehensive systematic review of English literature using PubMed was conducted, based on Preferred Reporting Items for Systematic Reviews and Meta-Analyses (PRISMA) guidelines. The used key words were: "inflammatory fibroid polyp" or "Vanek", including only cases with IFPs localized of the small intestine, published from 1976 to 2019.

Results: We present a case of a 38-year old patient with intestinal IFP presenting with acute abdomen due to intussusception diagnosed with ultrasound (US) based on a target sign and visible solid tumor in the small intestine leading to prompt surgical treatment. A diagnosis of IFP was made based on the pathohistological findings. Moreover, a systematic review of small intestine IFPs was conducted which is, to our knowledge, the first comprehensive systematic literature review on this topic. The analysis included 53 case reports or case series concerning 77 cases of small bowel IFPs. The patients were aged from 4 to 75 years (average 45.2 ), with a female predominance $(59.7 \%)$. The most common localization was the ileum in $77.9 \%$ cases, followed by the jejunum (13\%) and the duodenum (6.5\%). The most common clinical presentation was abdominal pain due to intussusception (63.6\%). Regarding diagnostic methods, computed tomography (CT) was frequently used as primary diagnostic method (26\%) followed by exploratory laparotomy (16.9\%), endoscopy (7.8\%) and US (6.5\%). Combination of US and CT contributed to the diagnosis in $9.1 \%$ of cases. The majority of cases were treated surgically (92.21\%), while only a minority benefited of minimally invasive techniques such as endoscopy. Conclusions: Small bowel IFPs, ones of the least common benign tumors, are characterized by variable clinical signs and symptoms and can potentially lead to serious consequences for the patient.
\end{abstract}

Key words: inflammatory fibroid polyp - small intestine - intussusception.

Abbreviations: CT: computed tomography; GI: gastrointestinal; IFP: inflammatory fibroid polyp; PDGFRA: platelet derived growth factor alpha; US: ultrasound.

\section{INTRODUCTION}

Inflammatory fibroid polyp (IFP), also known as Vanek's tumor, is one of the least common benign tumors of the gastrointestinal (GI) tract. It was first described in 1949 by Vanek [1] while the name IFP was proposed by Helwig and Ranier in 1953 [2, 3]. Even though IFPs can appear anywhere in the GI tract, the most common location is the gastric antrum and the ileum. The peak incidence is in the fifth and seventh decade, with a slight predominance in men [4]. Morphologic features of these tumors often vary, but their molecular pathogenesis has been well characterized. The majority of IFPs are found as solitary polyps, with an average diameter of 3 to $4 \mathrm{~cm}$, at the time of diagnosis. Many pathogenetic mechanisms have been put forward, such as metabolic, physical and chemical. However, after a recent discovery of platelet derived growth factor alpha (PDGFRA) mutations in these tumors [5], it became apparent that IFPs are true neoplasms, not as it was supposed reactive polyps, and their formation is triggered by activating mutations in the mentioned gene $[6,7]$. Clinical presentation depends both on the size and location of IFPs and can include acute or chronic abdominal pain, altered 
bowel habits, diarrhea, vomiting, GI bleeding and weight loss. Most gastric and colonic IFPs are asymptomatic; however, intestinal lesions can often present as intussusception [8]. Computed tomography (CT) is the most sensitive diagnostic method for mesenchymal GI tumors and can be used for suspected intussusception. Both colonic and gastric IFPs can be endoscopically diagnosed and removed, while intestinal IFPs are usually treated surgically especially when they present as acute abdomen [4].

We report a case of intestinal IFP presenting as acute abdomen due to intussusception. In addition, a systematic search was conducted in order to present the current knowledge of the IFPs of the small intestine reviewing demographic characteristics, clinical presentation, diagnosis and treatment.

\section{CASE REPORT}

A 38-year old patient presented in emergency department with complaints of abdominal pain located in the right hemiabdomen. First symptoms occurred 3 days prior to the presentation. The pain was initially generalized, increased post alimentary, subsequently with diarrhea. The patient was advised by the primary health care doctor to take analgesics and rehydrating solutions. Prior to arriving in emergency, the pain suddenly worsened in intensity from 3 to 8 on the analogue visual scale (one being no pain and 10 being the most intensive pain possible). An oral analgesic was taken before presenting to emergency, without effect. The patient denied any episode of nausea, vomiting and melena during the course of illness. There was no history of weight loss, though he complained of loss of appetite. Patient had an unremarkable drug, family or psychosocial history including smoking status and no history of previous GI illness.
On physical examination, the patient was afebrile, with abdominal tenderness on right hemiabdomen palpation, with rebound tenderness in the right iliac fossa and positive psoas sign. The Rovsing's sign was negative. The laboratory results were within the reference values. The chest radiography was normal, while abdomen radiography detected few air-fluid levels without signs of bowel distension.

The patient underwent a detailed ultrasound (US) examination that detected in the right lower quadrant of abdomen, the thickening of the intestinal wall of the small intestine with "target sign"; a solid tumor was clearly visible in the reported segment. Based on these findings the diagnosis of small bowel tumor with intussusception was made. Due to the severity of the pain refractory to analgesic opioid therapy, and to the US finding of target sign with solid tumor, the decision was made to perform urgent explorative laparotomy. During surgery, segmental resection of the small intestine, including a $3.5 \mathrm{~cm}$ long polypoid tumor, was made. The pathohistological analysis of the resected tumor revealed an inflammatory fibroid polyp of a the small intestine. The patient postoperative recovery was uneventful. Postoperatively the patient was relieved from pain. In the following weeks after surgery the bowel habits normalized. At two-year follow-up the patient is without abdominal complains.

\section{REVIEW OF THE LITERATURE}

The medical literature included in the systematic review was searched using the PubMed medical database. It included English-only literature, published between 1976 and 2019. A paper search was performed based on Preferred Reporting Items for Systematic Reviews and Meta-Analyses (PRISMA) guidelines (Fig. 1).
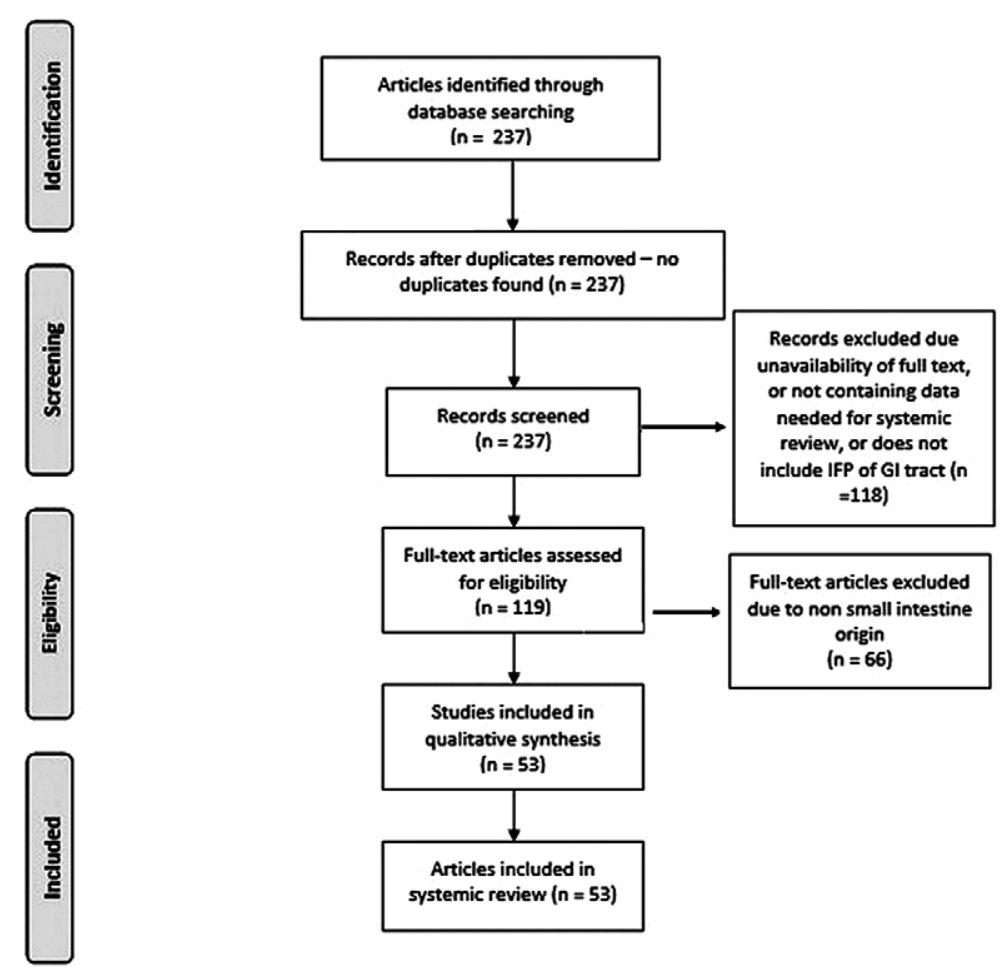

Fig. 1. PRISMA flow diagram of the article selection process. 
The search strategy included the terms "inflammatory fibroid polyp" or "Vanek", with filters: humans and Englishonly, and included only cases of IFP in the small intestine, to be more precise, the duodenum, jejunum and ileum. After a preliminary literature search, 237 articles were identified. Finally, the systematic review included a total of 53 case reports or case series, concerning 77 cases of IFPs localized in small intestine, published from 1976 to 2019. We collected the following data: age, gender, clinical presentation, location, tumor size, diagnostic tool and treatment. All articles that contain insufficient clinical and/or demographical data were excluded.

\section{RESULTS}

A total of 53 case reports or series concerning 77 cases of patients with IFPs of a small intestine were included in this review according to the aforementioned criteria. The main data systematically collected are presented in Supplementary Table I.

During analysis it was found that patients were aged from 4 to 75 years (average 45.2) and the majority of reported patients were female (59.7\%). The most common localization of IFPs in small intestine was the ileum (77.9\% cases) [9-47], followed by the jejunum (13\%) $[34,48-55]$ and the duodenum $(6.5 \%)$ [46, 56-59]. In $2.6 \%$ cases IFP was found in the ileal pouch [60, 61]. The most common clinical presentation was abdominal pain due to intussusception (63.6\%) [9-13, 16, 19, 21-23, 25, $26,29,30,32,34-38,40-43,45-49,53-55]$.

Regarding diagnostic methods, CT was frequently used as the primary diagnostic method $(26 \%)[9,10,12,13,15-17$, $23,24,27,28,30,35,48,49,51,53$ ] followed by exploratory laparotomy $(16,9 \%)[14,29,39,46,47,54]$, endoscopy $(7,8 \%)$ $[22,31,38,56,58,61]$ and US (6.5\%) [21, 41, 42, 44, 52]. Combination of US and CT contributed to the diagnosis in $9.1 \%$ of cases $[11,20,26,32,34,37]$. Only in two case reports the diagnostic tool was not specified $[33,45]$. Small intestine IFPs were in the majority of cases treated surgically (92.21\%), while only a minority were treated by minimally invasive techniques such as endoscopy.

\section{DISCUSSION}

Inflammatory fibroid polyps are rare, benign neoplastic lesions originating in the submucosa that arise through the GI tract. The precise etiopathogenesis remains still unknown. Several hypotheses were suggested about triggers that cause the formation of IFPs. It has been speculated that IFPs are a consequence of a chronic irritation or inflammation. Other authors suggested a possible relation with localized eosinophilic infiltration, since IFPs are characterized by predominate eosinophilic infiltrates [4]. Several cases have associated these lesions with Crohn's disease [30, 33, 62]. The discovery of PDGFRA mutations in IFPs in 2008 confirmed the neoplastic nature of these tumors. Among the case series, the frequency of mutations varies from $21.7 \%$ to $69.6 \%[4,5]$.

Inflammatory fibroid polyps originate from submucosa and are characterized by vascular and fibroblast proliferation with inflammatory response. The inflammatory infiltration includes dominantly eosinophils. IFPs are composed of mononuclear, spindle-shaped cells arranged in whorls or in an onion skin like fashion around mucosal glands and capillaries. The matrix can be collagen rich or consist of fine fibrillar collagen. Macroscopically, IFPs can be peduncular or sessile varying from 0.2 to $20 \mathrm{~cm}$ in diameter [4, 63-65]. Immunohistochemically, IFPs are positive for smooth muscle actin, CD68 and CD34 and negative for S100 protein, CD117 and cytokeratin AE1/AE2. On the other hand, gastrointestinal stromal tumors (GISTs) are positive for CD117, schwannomas for S100 protein and inflammatory myofibroblastic tumors are negative for CD34 $[8,66]$. The distinction to GISTs is based on different morphology and clinical behavior, although both lesions frequently have PDGFRA mutations [7].

Inflammatory fibroid polyps can appear through the whole GI tract. The most common site is the gastric antrum (66-75\%), followed by the small intestine, mainly the ileum (18-20\%), colorectal region (4-7\%), gallbladder (1\%), esophagus (1\%) and appendix $(<1 \%)[21,67,68]$.

Clinical presentation of IFPs depends mostly on location in the GI tract and their size. Patients with IFPs are usually asymptomatic and remain undiagnosed or IFPs are accidental findings during endoscopy or laparotomy procedures performed for another reasons. In case of gastric IFPs, chronic or mild abdominal pain is the most prominent symptom. Small intestine IFPs can present as severe acute abdominal pain, often due to intussusception, as revealed by our systemic review. However, most common clinical presentation of intestinal IFPs is occasional chronic colic-like abdominal pain, due to partial obstruction of the small intestine $[4,21,69]$. Other symptoms, such as chronic diarrhea, vomiting, alterations in bowel habits, tenesmus, GI bleeding, anemia or weight loss are less frequent $[21,70]$.

Diagnosing IFP can be challenging due to the nonspecific clinical presentation, highly dependent on the lesion site. It is based on medical history, physical examination and specific procedures such as X-ray, abdominal US, CT, magnetic resonance imaging (MRI), enteroclysis, endoscopy, video capsule procedure and angiography $[4,21]$. In severe clinical presentation or when intussusception is suspected but not confirmed by preoperative workup, diagnostic laparoscopy is needed to confirm the diagnosis. Exploratory laparotomy might also be indicated but diagnostic laparoscopy is less traumatic [4,71].

Abdominal X-ray is usually the first diagnostic method since most of the patients present with obstructive abdominal symptoms, but rarely establishes the diagnosis $[72,73]$. Enteroclysis was the gold standard for diagnosing intussusception until mid-1980. Although it has high sensitivity and specificity for both intraluminal masses and small mucosal lesions, nowadays it is rarely used due to its invasive nature [4, 21]. At present, US is regarded as the primary imaging modality to diagnose intraabdominal masses, because it is noninvasive and widely accessible. Intussusception, the common, yet serious clinical presentation of IFPs, can be diagnosed or excluded with US with a sensitivity of $98-100 \%$, a specificity of $88 \%$ and a negative predictive value of $100 \%$. Classical imaging appearances of intussusception would be the target or doughnut sign in the transverse view and sandwich, pseudokidney or hayfork sign in the longitudinal view. However, meteorism and 
obesity can limit the diagnostic accuracy $[4,74,75]$. Abdominal $\mathrm{CT}$, unaffected by the gas presence, is considered the most sensitive method to diagnose intussusception with a diagnostic accuracy of 58-100\% [21,76]. Pathognomonic intussusception appearance is bowel-within-bowel configuration suggested by vessels and mesenteric fat compressed between the small intestine walls. Therefore, it is recommended to perform CT as a routine diagnostic measure in patients presenting with intestinal obstruction $[21,77]$. Magnetic resonance imaging, not routinely performed in the patients with intestinal obstruction due to the price and to the scanning duration, can contribute to the diagnosis. Beall et al. [75] demonstrated that the cause of intestinal obstruction was correctly diagnosed by CT in $71 \%$ and by MRI in $95 \%$ of cases. The sensitivity, specificity and accuracy for helical CT in their report was $71 \%, 71 \%$ and $71 \%$ as compared to $95 \%, 100 \%$ and $96 \%$ for MRI $[4,75]$.

Inflammatory fibroid polyps can be diagnosed and treated with endoscopy, such as gastroscopy and colonoscopy, primarily when gastric or colonic involvement of IFP is suspected. Intussusception can be visualized during colonoscopy as an intraluminal mass directed centrally and distally, but such a diagnosis is rarely made $[21,75]$. Capsule endoscopy and double-balloon endoscopy are novel endoscopic methods for small intestine examination. Obstructive symptoms are a contraindication for capsule endoscopy, but it can be useful in cases with long-lasting abdominal pain with negative results on other endoscopic and radiologic exams. Doubleballoon endoscopy can be used to examine $70-150 \mathrm{~cm}$ of the small intestine, but its usage is limited [4]. Most IFPs can be endoscopically removed using endoscopic submucosal dissection $[4,78]$. Inflammatory fibroid polyps are considered benign and rarely recur or metastasize. Therefore, further diagnostics and follow up are not recommended. However, recently three case reports have been published that showed the invasion of IFP through the muscularis propria layer, one in the ileum [79] and two in the stomach $[66,80]$.

Small bowel IFPs are primarily treated surgically, as shown in our systematic review in $92.21 \%$ of cases. The surgical treatment is not recommended unless the tumor is symptomatic. Exploratory laparoscopy or laparotomy are first choices in cases of intussusception. In case of complete bowel obstruction, the surgical treatment should be performed as soon as possible in order to prevent the development of ischemia, necrosis and possible subsequent perforation of invaginated bowel segment.

\section{CONCLUSIONS}

This analysis of small intestine IFPs, to our knowledge, is the first comprehensive systematic literature review emphasizing that despite their benign nature, intestinal IFPs are characterized by the variability of the clinical signs and symptoms and can potentially lead to serious consequences for the patient.

Conflicts of interest: None to declare.

Authors' contributions: N.I. conceived and designed the study and drafted the manuscript. V.I., V.T. and L.V. searched the literature, analyzed the data, drafted the manuscript. F.L., R.S. and M.Z. critically revised the manuscript. D.S. supervised the study, critically revised the paper and approved the final version.

Supplementary material: To access the supplementary material visit the online version of the J Gastrointestin Liver Dis at http://dx.doi. org/10.15403/jgld-2417

\section{REFERENCES}

1. Vanek J. Gastric submucosal granuloma with eosinophilic infiltration. Am J Pathol 1949;25:397-411.

2. Onişor DM, Boeriu AM, Mocan SL, Bartha JR, Coroş MF, Dobru ED Vanek's tumor: a rare cause of gastric outlet obstruction. Case report and literature review. Rom J Morphol Embryol 2018;59:563-568.

3. Helwig EB, Ranier A. Inflammatory fibroid polyps of the stomach. Surg Gynecol Obstet 1953;96:335-367.

4. Abboud B. Vanek's tumor of the small bowel in adults. World J Gastroenterol 2015;21:4802-4808. doi:10.3748/wjg.v21.i16.4802

5. Schildhaus HU, Cavlar T, Binot E, Büttner R, Wardelmann E, Merkelbach-Bruse S. Inflammatory fibroid polyps harbour mutations in the platelet-derived growth factor receptor alpha (PDGFRA) gene. J Pathol 2008;216:176-182. doi:10.1002/path.2393

6. Huss S, Wardelmann E, Goltz D, et al. Activating PDGFRA mutations in inflammatory fibroid polyps occur in exons 12, 14 and 18 and are associated with tumour localization. Histopathology 2012;61:59-68. doi:10.1111/j.1365-2559.2012.04203.x

7. Lasota J, Wang ZF, Sobin LH, Miettinen M. Gain-of-function PDGFRA mutations, earlier reported in gastrointestinal stromal tumors, are common in small intestinal inflammatory fibroid polyps. A study of 60 cases. Mod Pathol 2009;22:1049-1056. doi:10.1038/modpathol.2009.62

8. Liu TC, Lin MT, Montgomery EA, Singhi AD. Inflammatory fibroid polyps of the gastrointestinal tract: spectrum of clinical, morphologic, and immunohistochemistry features. Am J Surg Pathol 2013;37:586-592. doi:10.1097/PAS.0b013e31827ae11e

9. Mader S, Ting J, Nabi H. Ileocolic intussusception from an inflammatory fibroid polyp: a rare cause of adult small bowel obstruction. ANZ J Surg 2019;89:E100-E101. doi:10.1111/ans.14086

10. Ekici U, Yilmaz S, Tatli F. Ileocecal invagination due to an inflammatory fibroid polyp. A case report. Ann Ital Chir 2018;89:347-349.

11. Forasté-Enríquez CF, Mata-Hernández R, Hernández-Villaseñor A, Alderete-Vázquez G, Grube-Pagola P. Intestinal obstruction in adults due to ileal intussusception secondary to inflammatory fibroid polyp: A case report. Rev Gastroenterol Mex 2017;82:263-265. doi:10.1016/j. rgmx.2016.03.006

12. Basara I, Canda AE, Sagol O, Obuz F, Secil M. Intussusception and perforation due to an inflammatory fibroid polyp located in the ileum. Wien Klin Wochenschr 2016;128:731-734. doi:10.1007/s00508-0161073-y

13. Romano-Munive AF, Barreto-Zuñiga R, Rumoroso-García JA, RamosMartínez P. Inflammatory fibroid polyp of the gastrointestinal tract: 10 years of experience at the Instituto Nacional de Ciencias Médicas y Nutrición Salvador Zubirán. Rev Gastroenterol Mex 2016;81:134-140. doi:10.1016/j.rgmx.2016.03.001

14. Khadanga S, Dugar D, Khurana U, Satapathy SP. Inflammatory fibroid polyp (Vanek's tumour): my worst nightmare in the emergency department. BMJ Case Rep 2016;2016:bcr2015213688. doi:10.1136/ bcr-2015-213688 
15. Laskaratos FM, Vlachou E, Luong TV, et al. Endoscopic resection of a giant ileal inflammatory fibroid polyp by retrograde double-balloon enteroscopy. Endoscopy 2016;48 Suppl 1 UCTN:E14-E15. doi: 10.1055/ s-0035-1569649

16. Sakran N, Farkash I, Hershko D. Inflammatory fibroid polyp (Vanek's tumour) causing a rare form of double invagination intussusception of the small bowel. ANZ J Surg 2018;88:E85-E86. doi:10.1111/ans.13261

17. Hiremath S, Nanjappa N, Kamath S. Inflammatory fibroid polyp (IFP) of the terminal ileum presenting as acute intestinal obstruction without intussusception. BMJ Case Rep 2015;2015:bcr2015211029. doi:10.1136/ bcr-2015-211029

18. Smith-Chakmakova F, Liu YJ, Karamchandani DM. Inflammatory Fibroid Polyp of the Ileocecal Valve: Case Report, Review, and Recent Advances. Ann Clin Lab Sci 2015;45:441-445.

19. Feldis M, Dilly M, Marty M, Laurent F, Cassinotto C. An inflammatory fibroid polyp responsible for an ileal intussusception discovered on an MRI. Diagn Interv Imaging 2015;96:89-92. doi:10.1016/j. diii.2014.01.013

20. Nerli RB, Jali SM, Guntaka AK, Malur PR, Anita B, Hiremath MB. Giant inflammatory fibroid polyp of the terminal ileum presenting with lower urinary tract symptoms: Case report. Indian J Cancer 2014;51:541-542. doi:10.4103/0019-509X.175304

21. Akbulut S. Intussusception due to inflammatory fibroid polyp: a case report and comprehensive literature review. World J Gastroenterol 2012;18:5745-5752. doi:10.3748/wjg.v18.i40.5745

22. Lasithiotakis K, Grisbolaki E, Filis D, Athanasakis I, Zoras O, Chalkiadakis G. Ileocolic intussusception precipitated by diagnostic colonoscopy: a case report. Surg Laparosc Endosc Percutan Tech 2012;22:161-163. doi:10.1097/SLE.0b013e31824b230f

23. Rabbani K, Narjis Y, Jgounni R, et al. Adult intussusception caused by an inflammatory fibroid ileal polyp. Acta Chir Belg 2012;112:157-159. doi:10.1080/00015458.2012.11680815

24. Yoon DW, Lee BJ, Lee JH, et al. A case of giant inflammatory ileal polyp removed by double-balloon enteroscopy. Clin Endosc 2012;45:198-201. doi:10.5946/ce.2012.45.3.198

25. Segovia-Lohse HA. Adult intussusception with perforation and secondary peritonitis. Case report. Cir Cir 2011;79:252-277.

26. Morales-Fuentes GA, de Ariño-Suárez M, Zárate-Osorno A, RodríguezJerkov J, Terrazas-Espitia F, Pérez-Manauta J. Vanek's polyp or inflammatory fibroid polyp. Case report and review of the literature. Cir Cir 2011;79:242-267.

27. Wolff JH, Twaddell WS, Darwin PE. Endoscopic resection of an ileal inflammatory fibroid polyp using retrograde single-balloon enteroscopy. Clin Gastroenterol Hepatol 2009;7:e66-e67. doi:10.1016/j. cgh.2009.07.004

28. Ruffolo C, Scarpa M, Bassi D, Angriman I. Inflammatory fibroid polyp causing intestinal obstruction following restorative proctocolectomy for ulcerative colitis. Dig Surg 2009;26:285-286. doi:10.1159/000227767

29. Costamagna D, Erra S, Zullo A, Servente G, Durando R. Small bowel intussusception secondary to inflammatory fibroid polyp of the ileum: report of a case. Chir Ital 2008;60:323-327.

30. Deschamps L, Bretagnol F, Couvelard A, Corcos O, Bedossa P, Panis Y. Inflammatory fibroid polyp in Crohn's disease revealed by ileoileal intussusception: case report and review of the literature. Inflamm Bowel Dis 2008;14:1317-1320. doi:10.1002/ibd.20446

31. Kim SG, Choi KD, Kim JS, Jung HC, Song IS. Ileal inflammatory fibroid polyp: a rare cause of obscure gastrointestinal bleeding diagnosed by wireless capsule endoscopy. Dig Dis Sci 2006;51:906-908. doi:10.1007/ s10620-006-9338-3
32. Karamercan A, Kurukahvecioglu O, Yilmaz TU, Aygencel G, Aytaç B, Sare M. Adult ileal intussusception: an unusual emergency condition. Adv Ther 2006;23:163-168. doi:10.1007/BF02850357

33. Parasi A, Triantafillidis JK, Barbatzas C, Karakosta A, Condilis N, Sotiriou H. Coexistence of Crohn's disease and inflammatory fibroid polyp of the small bowel. Report of a case and review of the literature. Ann Ital Chir 2005;76:395-399.

34. Bays D, Anagnostopoulos GK, Katsaounos E, Filis P, Missas S. Inflammatory fibroid polyp of the small intestine causing intussusception: a report of two cases. Dig Dis Sci 2004;49:1677-1680. doi:10.1023/b:ddas.0000043385.44842.c8

35. Savargaonkar P, Morgenstern N, Bhuiya T. Inflammatory fibroid polyp of the ileum causing intussusception: report of two cases with emphasis on cytologic diagnosis. Diagn Cytopathol 2003;28:217-221. doi:10.1002/ dc. 10258

36. Balci NC, Radjazi S, Polat H. Adult intussusception secondary to inflammatory fibroid polyp: demonstration by MRI. Eur Radiol 2000;10:1708-1710. doi:10.1007/s003300000508

37. Dicle O, Erbay G, Haciyanli M, Bora S. Inflammatory fibroid polyp presenting with intestinal invagination: sonographic and correlative imaging findings. J Clin Ultrasound 1999;27:89-91. doi:10.1002/ (sici)1097-0096(199902)27:2<89::aid-jcu8>3.0.co;2-u

38. Ojima Y, Okajima M, Asahara T, et al. Inflammatory fibroid polyp of the ileum with the appearance of a Borrmann type II lesion, caused by colostomy irrigation: report of a case. Surg Today 1997;27:1061-1063. doi:10.1007/BF02385789

39. Bradley B, Molloy PJ, Glick K, Kania RJ. Ileal intussusception and obstruction as presentation of inflammatory fibroid polyp. Dig Dis Sci 1995;40:812-813. doi:10.1007/BF02064984

40. De Foer B, Serrien B, Bleus E, et al. Inflammatory fibroid polyp of the ileum. Abdom Imaging 1993;18:363-365. doi:10.1007/BF00201783

41. Williams GR, Jaffe S, Scott CA. Inflammatory fibroid polyp of the terminal ileum presenting in a patient with active Crohn's disease. Histopathology 1992;20:545-547. doi:10.1111/j.1365-2559.1992. tb01045.x

42. Sampson MA, Lyons TJ, Nottingham J, Naik D. Ultrasound diagnosis of recurrent intussusception due to inflammatory fibroid polyp of the ileum. J Ultrasound Med 1990;9:423-425. doi:10.7863/ jum.1990.9.7.423

43. Suster S, Robinson MJ. Inflammatory fibroid polyp of the small intestine: ultrastructural and immunohistochemical observations. Ultrastruct Pathol. 1990;14:109-119. doi:10.1080/01913129009025123

44. Assarian GS, Sundareson A. Inflammatory fibroid polyp of the ileum Hum Pathol 1985;16:311-312. doi:10.1016/s0046-8177(85)80019-8

45. Nkanza NK, King M, Hutt MS. Intussusception due to inflammatory fibroid polyps of the ileum: a report of 12 cases from Africa. Br J Surg 1980;67:271-274. doi:10.1002/bjs.1800670414

46. Johnstone JM, Morson BC. Inflammatory fibroid polyp of the gastrointestinal tract. Histopathology 1978;2:349-361. doi:10.1111/j.1365-2559.1978.tb01727.x

47. McGregor JC, Rao SS. Inflammatory fibroid polyp of the ileum--a rare cause of intussusception. Postgrad Med J 1976;52:89-91. doi:10.1136/ pgmj.52.604.89

48. Kimura N, Hight M, Liang J, Willy R, Liang K, Camp J. Adult Intussusception Secondary to Inflammatory Fibroid Polyp. West J Emerg Med 2015;16:581-582. doi:10.5811/westjem.2015.4.26399

49. Joyce KM, Waters PS, Waldron RM, et al. Recurrent adult jejuno-jejunal intussusception due to inflammatory fibroid polyp - Vanek's tumour: a case report. Diagn Pathol 2014;9:127. doi:10.1186/1746-1596-9-127 
50. Miyata T, Yamamoto $\mathrm{H}$, Kita H, et al. A case of inflammatory fibroid polyp causing small-bowel intussusception in which retrograde double-balloon enteroscopy was useful for the preoperative diagnosis. Endoscopy 2004;36:344-347. doi:10.1055/s-2004-814305

51. Kuestermann SA, Saleeb SF, Teplick SK. General case of the day. Jejunal intussusception caused by an inflammatory fibroid polyp (IFP). Radiographics 1999;19:539-541. doi:10.1148/ radiographics.19.2.g99mr19539

52. Ling CC, Hsu TC, Shih SC, Kao CR, Chou SY, Huang SH. Inflammatory fibroid polyp of the jejunum causing intussusception: a case report. Zhonghua Yi Xue Za Zhi (Taipei) 1994;53:127-130.

53. Kim JS, Kwon SY, Byun KS, et al. Jejunal inflammatory fibroid polyp presenting as intussusception--a case report with review of the literature. Korean J Intern Med 1994;9:51-54. doi:10.3904/kjim.1994.9.1.51

54. Williams RM. An ultrastructural study of a jejunal inflammatory fibroid polyp. Histopathology 1981;5:193-203. doi:10.1111/j.1365-2559.1981. tb01777.x

55. Dalton MD, Vellios F, Goyal JK. Symptomatic inflammatory fibroid polyp of the small bowel: report of two cases with review of literature. South Med J 1977;70:298-301. doi:10.1097/00007611-197703000-00011

56. Inayat F, Khan MA, Zafar F, Munir A. Inflammatory fibroid polyp of the duodenum: is endoscopic resection a feasible therapeutic choice? BMJ Case Rep. 2018;11:e226972.

57. Calderon MG, Caivano VC, Bagnaresi S Jr, et al. A unique case of inflammatory fibroid polyp in the duodenum of a female adolescent: Case report and literature review. Medicine (Baltimore) 2017;96:e6131. doi:10.1097/MD.0000000000006131

58. Kröner PT, Council L, Mönkemüller K. Endoscopic characterization and resection of Vanek's tumor of the duodenum. Endoscopy 2015;47 Suppl 1 UCTN:E408-E409. doi:10.1055/s-0034-1392595

59. Wysocki AP, Taylor G, Windsor JA. Inflammatory fibroid polyps of the duodenum: a review of the literature. Dig Surg 2007;24:162-168. doi:10.1159/000102099

60. Widgren S, Cox JN. Inflammatory fibroid polyp in a continent ileo-anal pouch after colectomy for ulcerative colitis--case report. Pathol Res Pract 1997;193:643-647. doi:10.1016/S0344-0338(97)80044-1

61. Tysk C, Schnürer LB, Wickbom G. Obstructing inflammatory fibroid polyp in pelvic ileal reservoir after restorative proctocolectomy in ulcerative colitis. Report of a case. Dis Colon Rectum 1994;37:10341037. doi:10.1007/BF02049320

62. Theodoropoulos GE, Linardoutsos D, Tsamis D, et al. Gastrointestinal stromal tumor causing small bowel intussusception in a patient with Crohn's disease. World J Gastroenterol 2009;15:5224-5227. doi:10.3748/ wjg. 15.5224

63. Tudose I, Andrei F, Calu V, Stăniceanu F, Miron A. Giant inflammatory fibroid polyp. Rom J Intern Med 2012;50:179-185.

64. Mohamud SO, Motorwala SA, Daniel AR, Tworek JA, Shehab TM. Giant ileal inflammatory fibroid polyp causing small bowel obstruction: a case report and review of the literature. Cases J 2008;1:341. doi:10.1186/17571626-1-341
65. Akbulut S, Sevinc MM, Cakabay B, Bakir S, Senol A. Giant inflammatory fibroid polyp of ileum causing intussusception: a case report. Cases J 2009;2:8616. doi:10.4076/1757-1626-2-8616

66. Harima H, Kimura T, Hamabe K, et al. Invasive inflammatory fibroid polyp of the stomach: a case report and literature review. BMC Gastroenterol 2018;18:74. doi:10.1186/s12876-018-0808-9

67. Szczepanowski A, Kaluzniacki P, Mazurek A, Golyski J, Rudzki S. Inflammatory fibroid polyp of the small bowel causing intestinal obstruction due to intussusception-a case report. JPCCR 2009;3:122123.

68. Nonose R, Valenciano JS, da Silva CM, de Souza CA, Martinez CA. Ileal Intussusception Caused by Vanek's Tumor: A Case Report. Case Rep Gastroenterol 2011;5:110-116. doi:10.1159/000326930

69. Coulier B, Maldague P, Broze B, Gielen I. Ileal inflammatory fibroid polyp causing ileocolic intussusception. JBR-BTR 2008;91:149-152.

70. El Hajj II, Sharara AI. Jejunojejunal intussusception caused by an inflammatory fibroid polyp. Case report and review of the literature. J Med Liban 2007;55:108-111.

71. Yakan S, Caliskan C, Makay O, Denecli AG, Korkut MA. Intussusception in adults: clinical characteristics, diagnosis and operative strategies. World J Gastroenterol 2009;15:1985-1989. doi:10.3748/wjg.15.1985

72. Sundaram B, Miller CN, Cohan RH, Schipper MJ, Francis IR. Can CT features be used to diagnose surgical adult bowel intussusceptions? AJR Am J Roentgenol 2009;193:471-478. doi:10.2214/AJR.08.1801

73. Harned RK, Buck JL, Shekitka KM. Inflammatory fibroid polyps of the gastrointestinal tract: radiologic evaluation. Radiology 1992;182:863866. doi:10.1148/radiology.182.3.1535909

74. Sampson MA, Lyons TJ, Nottingham J, Naik D. Ultrasound diagnosis of recurrent intussusception due to inflammatory fibroid polyp of the ileum. J Ultrasound Med 1990;9:423-425. doi:10.7863/ jum.1990.9.7.423

75. Beall DP, Fortman BJ, Lawler BC, Regan F. Imaging bowel obstruction: a comparison between fast magnetic resonance imaging and helical computed tomography. Clin Radiol 2002;57:719-724. doi:10.1053/ crad.2001.0735

76. Marinis A, Yiallourou A, Samanides L, et al. Intussusception of the bowel in adults: a review. World J Gastroenterol 2009;15:407-411. doi 10.3748/wjg.15.407

77. Wang N, Cui XY, Liu Y, et al. Adult intussusception: a retrospective review of 41 cases. World J Gastroenterol 2009;15:3303-3308. doi:10.3748/wjg. 15.3303

78. Shaib YH, Rugge M, Graham DY, Genta RM. Management of gastric polyps: an endoscopy-based approach. Clin Gastroenterol Hepatol 2013;11:1374-1384. doi:10.1016/j.cgh.2013.03.019

79. Tajima S, Koda K. Locally infiltrative inflammatory fibroid polyp of the ileum: report of a case showing transmural proliferation. Gastroenterol Rep (Oxf) 2018;6:144-148. doi:10.1093/gastro/gow019

80. Lee JH, Yoo JS, Jung HY, et al. A case of invasion of Muscularis Propria of gastric inflammatory fibroid polyp. Korean J Helicobacter Up Gastrointest Res 2015;15:254-257. doi:10.7704/kjhugr.2015.15.4.254 